\title{
RAZVOJ INDUSTRIJE V MARIBORU S POSEBNIM POUDARKOM NA RAZVOJNIH DEJAVNIKIH
}

\author{
Andreja Slavec *
}

\section{IZVLEČEK}

UDK 911.33:338.45(497.12 Maribor)

Prispevek obravnava razvoj industrije v Mariboru po posameznih znaCilnih obdobjih. Posebej so izpostavljeni geografski, ekonomski in politǐ́ni dejavniki, ki so vplivali na razvoj industrije kot celote oziroma posameznih industrijskih panog.

ABSTRACT

UDC 911.33:338.45(497.12 Maribor)

THE DEVELOPMENT OF INDUSTRY IN MARIBOR WITH A SPECIAL STRESS ON DEVELOPMENT FACTORS

The items presents the development of industry in Maribor in its characteristical periods whit special stress on numerous geographical, economical and political factors, which have influenced the development of whole industry or special branches.

Maribor danes kljub vsem težavam, ki so posledica splošne gospodarske krize, se vedno velja za močan industrijski center v Republiki Sloveniji. Na njegov industrijski značaj in razvoj so vplivale stevilni politǐni in gospodarski dejavniki. Razvoj industrije je pušal sledove v mestnem organizmu in njegove posledice so vidne $v$ mestni zgradbi. Industrija je postala poseben prostorski sistem $\mathrm{v}$ mestu, njihov nelox̌ljiv del $\mathrm{z}$ mox̌nim dinamicnim nabojem. Industrializacija je od druge polovice 19.stolet ja mestu narekovala tempo razvoja in omogocila njegov hiter gospodarski, populacijski in prostorski razvoj. V tem skoraj stoletje in pol trajajocem razvoju lahko ločimo naslednja industrializacijska obdobja:

\section{OBDOBJE OD ZGRADITVE JUŽNE ŽELEZNICE DO LETA 1918}

V prvi polovici 19.stoletja je bil Maribor se pretežno agrarno in obrtno-trgovsko središce. Mesto se je razen redkih izjem š vedno držalo srednjeveskkega jedra. Manufakturni obrati, kot prvi znanilci nove industrijske dobe, so se pojavili že v prvi polovici 18.stoletja. $\mathrm{V}$ 80-tih letih tega stoletja pa je nastala prva velika manufaktura- vojaška oblacilnica (1784-1810) Avstroogrske monarhije. Odločilno vlogo pri nastanku tega obrata je imel položaj mesta na sticišcu pomembnih prometnih poti med Tirolsko, Notranjo Avstrijo in Vojno krajino. V prvi polovici 19.stoletja so $\mathrm{v}$ Mariboru odprli ße nekatere druge manjß̌ manufakturne obrate: tovarno svincenega glaja, vinskega kamna, pepelike in kavnih surogatov ter dve tovarni rozolja. Vexina manufakturnih obratov je bila razmešcena $v$ mestnem jedru in njegovem zahodnem

"Dipl. geog, mlada raziskovalka, Oddelek za geografijo, Filozofska fakulteta, Aškerčeva 12, 61000 Ljubljana, Slovenija 
predmestju.Tovarne, ki so svoje izdelke izvažale, so bile usmerjene $\mathbf{k}$ pristanu kot izhodišu dravske prometne poti. (Leskovec,1991)

$\mathrm{Z}$ odpravo fevdalizma(leta 1848), ki ga je na neagrarnem področju označevala cehovska prisila in državno vmesavanje $\mathrm{v}$ gospodarstvo, $\mathrm{z}$ izgradnjo železnic ( $\mathrm{v}$ obdobju od leta 1846 do 1864 ) in s politix̌no vkljuxitvijo predmestij, se je v Mariboru začelo novo obdobje industrijskega, trgovskega in upravnega razvoja. Gradnja železnic je sprožila veliko konjunkturo. Sprostitev gospodarske politike in ucinki zemljiske odveze pa so vodili $\mathbf{k}$ odpiranju novih trgovin, obrtnih delavnic in tovarn.

Poudariti je treba, da je železnica najpomembneje vplivala na razvoj industrije v tem obdobju. Maribor je z izgradnjo Južne železnice(1846-1849), na katero so leta 1860 priključili železniško progo do Madžarske in leta 1864 se koroško progo, postal pomembno prometno križiš̌e. Po drugi strani pa je izgradnja obeh kolodvorov, glavnega in studenškega, $\mathbf{v}$ graškem in magdalenskem predmest ju, pospešila tudi prostorsko Siritev industrije.

Za razvoj industrije so bile velikega pomena tudi obstoječe obrtne delavnice, manufakture in manjß̌e tovarne, ki so pomenile osnovo nadaljnje industrializacije. Železnica je pripeljala nove proizvode, zato so se obdržali le tisti obrtniki, ki so prešli na industrijski način proizvodnje in ki so lahko s svojimi izdelki konkurirali na domacem trgu.

Leta 1863 je bilo v Mariboru ustanovljeno prvo večje podjetje kovinske stroke- Delavnice Južne železnice. Zgradili so jih $\mathrm{z}$ avstrijskim kapitalom ob studenškem kolodvoru in so bile prvo industrijsko podjetje izven mestnega jedra. Odlocilna pri izbiri lokacije je bila prav gotovo osrednja lega mesta v sistemu Južne železnice. Zaposlovale so kvalificirano delovno silo s severa, ki je kasneje predstavljala strokovno osnovo za nadaljni razvoj kovinske industrije $\mathrm{v}$ mestu. Vse do konca druge svetovne vojne so bile Delavnice najvecje industrijsko podjetje v mestu in so leta 1890 zaposlovale že okrog 1200 ljudi.

Poleg Delavnic so $\mathbf{v}$ mestu prevladovale živilska, usnjarska in cevljarska industrija. Razvoj mlinske industrije, industrije rozolja in pivovarništva sta omogoxili agrarna okolica mesta in ugodne možnosti izvoza. Usnjarska in cevljarska industrija sta se razvili na temeljih večstoletne usnjarske tradicije, ki je v zadostnih kolixinah vode iz reke Drave in surovinah iz mestnega zaledja našla ugodne možnosti za svoj razvoj. (Leskovec,1991)

Ko je leta 1873 prišlo do dunajskega borznega poloma, se je tudi v Mariboru prekinil industrializacijski zagon. Od obstojecih podjetij se je Sirilo Scherbaumovo mlinsko podjetje, Franzov mlin in tovarna testenin, Gotzova pivovarna pa je postala najmodernejße podjetje $v$ svoji stroki na Spodnjem Štajerskem. Bogate zaloge lesa v mestni okolici so predstavljale osnovo za razvoj lesne industrije. Vzporedno s Sirjenjem mesta se je povecala tudi potreba po gradbenem materialu, zato so predvsem v okolici mesta in v Melju zgradili več opekarn. Pojavijo pa 
se tudi prva gradbena podjetja.(Leskovec,1991)

V Casu od leta 1873 do leta 1918 so odprli v Mariboru tudi obrate novih industrijskih panog. Leta 1878 se je iz stare milarske obrti razvila Brosova tovarna mila in mašob, ki so jo leta 1902 preselili v Melje. Franc Swaty je leta 1896 zacel izdelovati umetne bruse, ki so se zelo zgodaj uveljavili na domocem in tujem trgu. Mesto je leta 1902 dobilo še klavnico in železolivarno A.Bendla v Melju. Precej se je razvila tudi tiskarska dejavnost.(Leskovec,1991)

Med prvo svetovno vojno je mariborsko gospodarstvo povsem zastalo. Na začtku vojne razen Delavnic Južne železnice $v$ mestu ni bilo industrije, ki bi se lahko uspešno vkljuxila $v$ avstroogrsko vojno gospodarstvo. Le redka podjetja so krizo uspex̌no prebrodila s preusmeritvijo proizvodnje.

\section{OBDOBJE OD LETA 1918 DO LETA 1945}

Za prva povojna leta so znacilne zelo neurejene monetarne razmere. Nestabilnost na denarnem področju je povzrocila propad številnih podjetij. Poleg tega so se po prvi svetovni vojni pojavile na gospodarskem področju težave, ki so bile posledica novih državnih meja. Mariborska agrarna okolica je naenkrat ostala brez dotedanjega avstrijskega tržišca za svoje kmetijske pridelke. Trgovanje $v$ okviru nove države ni bilo mogoče, zaradi močne konkurence vzhodnih in južnih kmetijskih obmocij. Trgovina se je postopoma omejevala na mesto in okolico, tudi zaradi visokih prevoznih tarif. Kakor se je pred prvo svetovno vojno obrtna dejavnost morala umakniti trgovini, tako se je po vojni trgovina umaknila industriji in ji prepustila vodilno vlogo. (Kržǐnik,1956) Tuj kapital, predvsem avstrijski in Ceski je bil še vedno zainteresiran za naložbe pri nas. Mesto Maribor je ležalo v neposredni bližini carinske meje in je bilo se posebej privlačno ża tuje industrialce. Meja je namreč dražila blago, ki ga je bilo treba uvažati, zato ga je bilo ceneje proizvajati na tržišcu samem. V industrializaciji Maribora so imeli odločilno vlogo mariborski Nemci, ki so stimulativno vplivali na krepitev slovenske podjetniške miselnosti.(Leskovec,1991)

Pivovarništvo, usnjarska in mlinska industrija, ki so bile poleg kovinske industrije glavne industrijske panoge v mestu do leta 1918, v stari Jugoslaviji ne napredujejo vec. Vse tri panoge so podlegle močni domaci in tuji konkurenci.

Popolnoma nasproten pojav zasledimo pri razvoju tekstilne in kovinske industrije, ki sta $\mathbf{v}$ tem obdobju postali vodilni industrijski panogi v mestu. Njun razvoj so vzpodbudili naslednji dejavniki:

- prometna lega ob Južni železnici, ki tu prehaja državno mejo;

- dovolj elektrixne energije s falske elektrarne, ki je zacela obratovati leta 1918; v drugi fazi industrializacije je imela elektrixna energija podoben pomen kot železnica v prvi fazi; 
- cenena in marljiva delovna sila, ki je imela bogato obrtniško tradicijo;

- gopodarska politika stare Jugoslavije, ki je z ugodno zašcito pridobila tuj kapital. Le-ta je v Mariboru, zaradi njegove ugodne lege,cenene delovne sile, elektrixne energije in poceni zazidalnih povrsin,videl ugodne možnosti za razvoj industrije. (Kržǐnik, 1956)

Tekstilno industrijo sta v Maribor pripeljala Cě̌ka tovarnarja Schonsky in Loebl, ki sta leta 1921 na Oreškem nabrežju ustanovila tkalnico in apreturo, kasne jšo Mariborsko tekstilno tovarno. Po tem letu so v Mariboru ustanovili క̌tevilna veð̌a in manjæa tekstilna podjetja. Kriza, ki se je pri nas pojavila leta 1931 se je tekstilne industrije komajda dotaknila. Konjunktura na notranjem jugoslovanskem tekstilnem tř̌išu, ki je bilo s svetovnim trgom slabo povezano, je vplivala na manjše posledice gospodarske krize na to industrijsko panogo. Tekstilna industrija se je med in po krizi razvijala $\mathrm{z}$ nezmanjふ̌sano hitrostjo.Vanjo je bilo vloženega največ そeškega kapitala,sledil je domađi nemški in židovski kapital. Slovenci so bili večnoma lastniki manjših konfekcijskih obratov. Konec leta 1938 je imel Maribor najvec industrijskih obratov v Sloveniji. 6293 delavcev je bilo zaposlenih v 27 tovarnah, kar je bilo kar $35,7 \%$ vseh v testilni industriji zaposlenih delavcev Slovenije. Tekstilna industrija je bila zelo navezana na uvoz surovin, zato je imela vse od zacetka druge svetovne vojne velike težave. (Leskovec, 1991)

Med obema vojnama se je kot nova panoga razvila kovinska industrija. Kljub zgodnjim zaCetkom(1863) pa kovinska industrija niti po številu obratov, niti po številu zaposlenih, ni dosegla tekstilne industrije. Najvecje podjetje te stroke so bile še vedno Delavnice državnih železnic, ki pa so imele $\mathbf{v}$ državi nov, periferen položaj, zato lastnica- Jugoslovanske državne železnice, ni bila zainteresirana za modernizacijo tovarne. Kljub temu so delavnice $\mathrm{v}$ tem casu zaposlovale že od 2100 do 2500 delavcev. Ustanovili so tudi Stevilna nova podjetja kovinske stroke. V vsej kovinski industriji je bilo zaposlenih 3700 delavce. Skoraj vsa podjetja so bila v rokah domaxih Nemcev.(Leskovec,1991)

V prvih povojnih letih je konjunktura pospesila nastanek vecjega števila lesno predelovalnih obratov, saj so elektriðna energija, dobre železniske povezave, plovna reka Drava ter z lesom bogata okolica Maribora predstavljale ugodne pogoje za razvoj te industrijske panoge. Kriza v 30-tih letih 20.stoletja je lesno industrijo moxno prizadela; క̌tevilna podjetja so propadla, $v$ casu do druge svetovne vojne pa niso ustanovili nobenega novega lesnega obrata.(Leskovec,1991)

Na osnovi povpraševanja na trgu in razvoja nove tehnologije je prišlo tudi do napredka starih industrijskih podjetij, npr. Tovarne umetnih brusov Swaty in tovarne Zlatorog, ki je nenehno Sirila svoj proizvodni program.Med obema vojnama je nastalo se nekaj manjsih kemičnih tovarn, Maribor pa je dobil tudi rafinerijo mineralnega olja.(Leskovec,1991)

Kljub pricakovanjem, da se bo $v$ mestu,zaradi bližine falske HE, razvila elektrotehnǐ̌na industrija, je bilo leta $1941 \mathrm{v}$ mestu le eno podjetje te stroke. 
Nasprotno pa velja za graficno industrijo, ki se je v tem Casu precej okrepila.

Na zað̌etku tega poglavja smo omenili kako pogubno so nove državne meje vplivale na razvoj mlinske industrije in pivovarništva. Enako pa velja tudi za vso ostalo živilsko industrijo. Predelava kmetijskih pridelkov, ki jih je mariborska okolica nudila v izobilju, je bila Sibka. Vzroke lahko išcemo v protekcionistǐni politiki držav srednje Evrope, ki je strmela za avtarkijo na vseh podroxjih. Domaxi trg pa za predelane živilske produkte ni bil dovzeten, saj je imel na razpolago dovolj svežih pridelkov. Med vojnama oživi predvsem proizvodnja žganih in brezalkoholnih pijac, proizvodnja cokolade, kanditov, pecilnega praska, kavnih nadomestkov in mesnih izdelkov, vendar so bili ti industrijski obrati zve飞ine manjši.

Nagla medvojna industrializacija je imela svoje ucinke tudi v prostoru. $\mathrm{V}$ tem casu je bil politǐni teritorij mesta gradbeno že precej nasicen in industrija se je začela Siriti na izvenmestno obmoxje. Vexina veðjih industrijskih obratov je bila locirana $v$ meljski in tezenski industrijski coni, ob Tržaški cesti in v bližini koroškega kolodvora na Studencih. Manjłi obrati pa so bili razporejeni po starem delu mesta in na njegovem zahodnem obrobju.

Med drugo svetovno vojno so mariborsko industrijo vkljucili v nemsko vojno proizvodnjo. Leta 1941 so Nemci v tezenskem gozdu zgradili tovarno letalskih delov (današnji TAM), ki je danes največje podjetje $v$ mestu. Nastalo je tudi novo podjetje kovinske stroke-Remont(današnja Strojna), znatno pa je razsirila svoje kapacitete tudi Metalna. Med vojno so Nemci zaceli graditi tudi HE Mariborski otok. Maribor je bil kot prometno in gospodarsko središce tarča Številnih bombnih napadov, ki so bili v glavnem usmerjeni na železniški most ter industrijske objekte $v$ Melju, na Studencih in Teznu. Maribor je bil najbolj porušeno slovensko mesto in tudi industrija je utrpela ogromno Skodo.

\section{OBDOBJE PO DRUGI SVETOVNI VOJNI}

\subsection{OBDOBJE OBNOVE IN PRVE PETLETKE OD LETA 1945 DO LETA 1951}

Po vojni se zarne novo obdobje gospodarskega razvoja. Kljub tehnološki zastarelosti industrije je Maribor v povojno obdobje vstopil kot eden, izmed najpomembnejsih industrijskih središc $\mathbf{v}$ državi. Prva leta so potekala $\mathbf{v}$ duhu obnove, nacionalizacije in prve petletke.

Leta 1945 in 1946 so obnovili ve`ino glavnih industrijskih objektov iz predvojne dobe, tako da je bila leta 1947 že skoraj dosežena predvojna raven proizvodnje. Leta 1946 se je zacela nacionalizacija industrijskih objektov in proizvodnih sredstev. Posledica tega je bila fuzija velikega Stevila industrijskih obratov iste stroke $\mathbf{v}$ nova, vecja podjetja. V Mariboru so nacionalizirali 60 vecjih in manjßih tovarn ter jih povezali v 35 novih podjetij. $V$ ta podjetja so vkljucili se enajst industrijskih obratov iz okoliskih krajev, enajst obrtnih delavnic ter pet tovarn, ki so bile ustanovljene med drugo svetovno vojno. Posledica tega je bila velika razpršenost industrijskih 
obratov pó celotnem mestnem prostoru. Podjetja so imela proizvodnjo organizirano na razlicnih lokacijah, saj je bilo $\mathrm{v}$ tem obdobju malo novogradenj, ki bi omogoxile prostorsko koncentracijo industrijske proizvodnje. $\mathrm{V}$ osemnajstih podjetjih se je proizvodnja odvijala na eni lokaciji, v preostalih sedemnajstih pa na 56 razliennih lokacijah, kar prav gotovo ni imelo pozitivnih uxinkov. Oteženo je bilo komuniciranje, manjše so bile možnosti smotrne organizacije proizvodnega procesa in vě̌ji so bili transportni stroški.

Leta 1947, ko je bila obnova že skorajda koňana in je bila nacionalizirana vecina podjetij, ter dosežena predvojna raven proizvodnje, so bili dani pogoji za izvedbo prvega petletnega gospodarskega plana. $\mathbf{V}$ tem Casu je mariborska industrija oddajala precejšen del svoje akumulacije za razvoj drugih manj razvitih krajev in obmoxij. Tekstilna industrija je na primer odvajala velik del svoje akumulacije, ceprav so bila njena proizvodna sredstva mocno zastarela in nujno potrebna modernizacije. $\mathrm{V}$ teh letih se je že začela določena stagnacija $\mathbf{v}$ mariborskem gospodarstvu.

Razvoj industrije je bil $\mathrm{v}$ tem obdobju tesno povezan $\mathrm{z}$ gradnjo hidroelektrarn na Dravi. Leta 1948 je zacela obratovati HE Mariborski otok, ki je bila skupaj z ostalimi HE pomemben dejavnik nadaljne industrializacije.

Do leta 1951 se je v Mariboru razvilo trinajst industrijskih panog $(20 \mathrm{v}$ Sloveniji). Kot nova panoga se pojavi elektroindustrija(podjetje Elektrokovina), stevilna podjetja pa so zacela izdelovati tudi nove proizvode. Po drugi svetovni vojni je vodilno mesto v Mariboru prevzela kovinska industrija, ki je leta 1951 zaposlovala skoraj polovico industrijskih delavcev oziroma $41,7 \%$ vseh v kovinski industriji zaposlenih delavcev v Sloveniji. Ustvarila je vec kot $30 \%$ industrijskega družbenega proizvoda( $\mathrm{v}$ nadaljevanju DP) mesta. Na nagel razvoj kovinske industrije so prav gotovo vplivale bogate zaloge električne energije na Dravi in strokovna delovna sila.

Tekstilna industrija je po letu 1945 zasedla drugo mesto po stevilu zaposlenih(30\% vseh industrijskih delavcev $\mathrm{v}$ mestu), vendar je ustvarila ve` kot $50 \%$ industrijskega DP mesta. Kljub manjšemu številu zaposlenih je imela tekstilna industrija še vedno osrednji položaj v mariborskem gospodarstvu.

Tema dvema panogama so po కttevilu zaposlenih sledile lesna industrija, elektroindustrija in kemiŁna industrija. Grafið̌na, papirna in živilska industrija so imele lokalni znacaj. Usnjarska industrija s sedemstoletno tradicijo je popolnoma izgubila na pomenu.

Za celotno industrijo je znaxilno, da je imela precej veð kapacitet, kot jih je izkoriš̌ala. Vzroki so bili predvsem $\mathrm{v}$ zastarelosti strojnega parka, ozkih grlih, ki so bila posledica nenacrrtne gradnje industrijskih obratov v predvojni dobi in nihanju proizvodnje električne energije v sušnih obdobjih. Fizǐ̌na izrabljenost proizvodnih sredstev je bila nad $50 \%$. Na slabo izkorišcanje 
proizvodnih kapacitet pa je vplivalo tudi pomankanje surovin, njihova slaba kvaliteta in ekonomska blokada $\mathrm{v}$ casu informbiroja. Nadaljna znacilnost industrijske proizvodnje je bilo pomanjkanje kvalificirane delovne sile in velik priliv nekvalificirane delovne sile, kar je negativno vplivalo na produktivnost dela.

V tem obdobju ni prišlo do vexjih prostorskih sprememb. Slika predvojne prostorske razpršenosti industrijskih obratov se je po vojni vendarle nekoliko izboljłala, predvsem na racun propada velikega števila manjsih industrijskih obratov. Do veðje koncentracije je prišlo v industrijski coni Melje, na Studencih v bližini kolodvora, na Taboru ob Tržaski cesti in na Teznu med železniško progo in Ptujsko cesto. V samem centru mesta je bilo razpršeno večje število manjših industrijskih obratov. $\mathrm{V}$ industrijski coni Melje so bile locirane predvsem tekstilna in kovinska industrija, pa tudi živilska, kemična, lesna industrija in industrija papirja. $\mathrm{Na}$ Studencih so se ohranile že tradicionalne kovinska, tekstilna, mlinska in papirna industrije. $\mathrm{Na}$ Teznu, kjer sta se kovinska in tekstilna industrija naselili že pred drugo svetovno vojno, so leta 1948 postavili tudi prvo vecje elektrotehnǐ̌no podjetje (Elektrokovina). Na lokacijah v centru mesta( živilska, grafið̌na, lesna industrija, industrija gradbenega materiala) nadaljni prostorski razvoj ni bil možen. Nekoliko vecje in lokacijsko ustreznejše jedro pa se je izoblikovalo ob Tržaški cesti.

\subsection{OBDOBJE SAMOUPRAVNEGA GOSPODARSTVA OD LETA 1951 DO LETA 1971}

Na razvoj gospodarstva $v$ tem obdobju so vplivali razlǐni politični in ekonomski dejavniki. Da bi onemogocili krepitev države so leta 1950 sprejeli zakon s katerim je bilo uvedeno samoupravljanje, ki so ga leta 1953 potrdili \e z ustavo. Vendar pa je država š vedno posegala v gospodarstvo, zato je bilo samoupravljanje le nominalno, gospodarski sistem pa državno administrativen. S postopnim večanjem pristojnosti podjetij pri gospodarjenju oziroma s tako imenovano decentralizacijo od leta 1958 dalje pa je nastal tržni sistem samoupravnega socializma, ki je vidno izboljæ̌l gospodarske rezultate. (Bajt,1989,306)

$\mathrm{Z}$ gospodarsko reformo leta 1965 se začne obdobje uvoza tujega kapitala, kar je omogoxilo razvoj novih industijskih panog in krajev (Titovo Velenje, Novo Mesto, Nova Gorica). To obdobje je bilo za tradicionalno predelovalno industrijo, kakršna je bila v Mariboru,sila neugodno. Za industrijo Maribora lahko rečemo, da v tem obdobju že kaže znake zaostajanja za industrijskim razvojem v republiki. Med vzroki in dejavniki za takšno stanje naj omenimo:

- Investicijska vlaganja $\mathrm{v}$ mariborsko industrijo so bila skromna, saj se je $\mathrm{v}$ tem Casu investiralo predvsem $\mathrm{v}$ manj razvita obmoxja. Veðino naložb $\mathrm{v}$ mariborsko industrijo so financirali iz lokalnih virov; vlagalo se je pretežno $\mathrm{v}$ kovinsko, tekstilno in živilsko industrijo s ciljem odprave ozkih grl. Rezultat tega sta bili visoka stopnja fiziene izrabljenosti proizvajalnih sredstev, ki je bila veliko višja kot $\mathbf{v}$ Sloveniji in Jugoslaviji, ter pođasna modernizacija.

- Industrija Maribora je zrasla iz majhnih, lokacijsko neustreznih, manjگih industrijskih obra- 
tov, katerih razvoj je temeljil na strokovni fizienni delovni sili, ki je je bilo v Mariboru in okolici dovolj. Mesto je imelo v primerjavi s Slovenijo veliko slabšo kvalifikacijsko strukturo delovne sile, $\mathrm{kar}$ je vplivalo na produktivnost in prispevalo $\mathrm{k}$ stagnaciji industrije.

- Pomemben dejavnik je bila tudi razdrobljenost in zaprtost industrijskih podjetij. Stopnja specializacije in delitve dela med podjetji je bila Sibka.

- Tudi pomanjkanje "podjetniške klime" in razvojnih konceptov je direktno in indirektno vplivalo na razvoj industrije.

- Slabo razvita okolica mesta in gospodarsko nerazvite sosednje obCine so prav tako negativno uxinkovale na razvoj mestne industrije, saj je bilo osem izmed dvanajstih sosednjih obcin gospodarsko slabo razvitih. Po drugi strani pa je tudi mariborska industrija sama premalo naredila za razvoj industrijskih obratov $\mathrm{v}$ svoji okolici.

Vsi našteti dejavniki so negativno vplivali na rast industrijske proizvodnje in razvoj industrije nasploh. Industrializacija je potekala pod vplivom treh panog: kovinske, tekstilne in elektroindustrije. $\mathrm{V}$ prvih letih tega obdobja se je proizvodnja mocno povecala, kar je bila posledica boljక̌ega izkoriš̌anja kapacitet, odprave ozkih grl in delno tudi novih kapacitet. Do leta 1956 se je proizvodnja povečvala predvsem na raču dodatnega zaposlovanja, po letu 1956 pa pretežno na racun povecane delovne storilnosti. Mariborska industrija je bila zelo navezana na Sirß̌i gospodarski prostor, tako domað kot tuj. Nestabilnost na tržiš̌u je povzroð̌ila stagnacijo, ki se je zacela leta 1960 in je trajala vse do leta 1967. V tem obdobju je precej napredovala elektroindustrija, na kar je vplival celoten napredek jugoslovanskega gospodarstva, povecanje kupne mox̌i prebivalstva in osvajanje zunanjega tržišca. Napredovala je tudi predelava nekovinskih rudnin, kemiena in lesna industrija. Tudi živilska industrija je precej razsirila paleto svojih proizvodov. Po letu 1967 je oživela investicijska dejavnost in industrijska proizvodnja je zacela počasi narašati. Podjetja so se zacela intenzivneje vključevati v mednarodno menjavo, povečala pa se je tudi storilnost. Pojavila se je cela vrsta nadpovprě̌no ekspanzivnih podjetij (TAM, Zlatorog, Primat, Marles, Mariborska livarna, Konstruktor, Stavbar, Hidromontaža) z napredno usmerjenimi vodilnimi in strokovnimi kadri.

V tem Casu se je nekoliko izboljšala tudi kvalifikacijska struktura zaposlenih, kar je bila posledica ustanovitve visokošolskih zavódov $\mathbf{v}$ Mariboru. Istocasno so se oblikovale tudi razvojne in raziskovalne ustanove, ki so tesno sodelovale $\mathrm{z}$ gospodarskimi organizacijami pri reševanju problemov proizvodnje, poslovanja in razvoja. Centralizacija proizvodnje, ki se je zacela $\mathbf{v}$ preteklem obdobju se je nadaljevala tudi v tem.

Prostorski razvoj industrije med letoma 1951 in 1971 ni bil tako živahen kot v preteklosti. Podjetja so gradila nove proizvodne objekte in skladiša $\mathbf{v}$ glavnem na obstojecih lokacijah. Prostorska stiska jih je prisilila, da so se pogosto Šrila tudi na sosednja zemljiša. Na ta nađin se je večal delež industrijskih povrß̌in v mestu. Glavnina industrijskih podjetij je bila కe vedno locirana $\mathbf{v}$ industrijski coni Melje, kjer so se naselila Se nekatera nova podjetja. Prav tako se je Širila tudi industrija na Teznem, kjer so postavili tudi novo poslopje Industrijskega montažne- 
ga podjetja in na Studencih. Edino vecje novo industrijsko obmoxje je nastalo $\mathrm{z}$ ustanovitvijo lesnega podjetja Marles ob Limbuski cesti.

\subsection{OBDOBJE DOGOVORNE EKONOMIJE OD LETA 1971 DO LETA 1989}

Sistem združenega dela ali tako imenovan sistem dogovorne ekonomije je znova poslabふal gospodarske rezultate. Istocasno je prišlo do organizacijskih sprememb v podjetjih, ki so jih razdelili na temeljne organizacije združenega dela ( $v$ (nadaljevanju TOZD). Pogosto so na TOZD-e razdelili prej organizacijsko in tehnološko enovita podjetja, kar je imelo številne negativne posledice. Proces "tozdiranja" je bil v Mariboru precej intenziven, posebej v velikih organizacijah zduženega dela v nadaljevanju OZD). Samo dvanajst OZD od Sestinpetdesetih se $\mathbf{v}$ ta proces ni vključilo. $\mathbf{V}$ večini primerov so bili TOZD-i prostorsko skoncentrirani na eni lokaciji, le v sestih OZD so bili TOZD-i tudi lokacijsko ločeni in so predstavljali zaključene industrijsko prostorske enote. Kot viša oblika združevanja so se $\mathbf{v}$ tem obdobju pojavile sestavljene organizacije združenega dela, ki povezujejo podjetja s sorodno proizvodno usmerjenostjo ( KEMA,TIMA,ELKOM,MTT).

Maribor je v tem obdobju še bolj zaostal za ostalimi industrijskimi središci. Tako je leta 1981 glede vseh pomembnejsih kazalcev ekonomske uspešnosti pristal šele na desetem mestu v Sloveniji. Na drugi strani pa je Stevilo zaposlenih, enako kot $\mathbf{v}$ preteklih obdobjih, Se vedno narašalo. Leta 1985 so $\mathrm{v}$ Mariboru se vedno govorili o deficitu zaposlenih $\mathrm{v}$ kovinski in tekstilni industriji. Delež industrije v DP mesta se je $\mathbf{v} 70$-tih letih znižal, kar je bila posledica organizacijskih in ekonomskih sprememb ter naftne krize. V 80-tih letih pa se je znova nekoliko dvignil, ter $\mathrm{v}$ zadnjih letih stagnira na $50 \%$.

Za 80-ta leta je znacilna pocasna rast industrijske proizvodnje, ki se giblje na robu stagnacije. $\mathrm{V}$ podjetjih so se kopicile zaloge. Akumulacija je izgubila tekmo $\mathrm{z}$ osebnimi dohodki. Visoki nominalni rasti proizvodnih stroškov so se podjetja prilagodila $\mathrm{z}$ upoðasnitvijo proizvodnje. Dinamiko in strukturo proizvodnje so vse manj opredeljevali fiziŁni faktorji, v vse vecji meri pa pogoji gospodarjenja. Vzroki so bili od podjetja do podjetja razlicni, vsekakor pa je predstavljala najvecji problem inflacija. Medtem, ko je $\mathbf{v} 70$-tih letih na rast proizvodnje vplivala oskrba s surovinami, postane v 80-tih letih( se posebej pa po letu 1985) vse bolj aktualen problem plasmaja gotovih izdelkov, kar je se posebej prizadelo lahko predelovalno industrijo.

Investicije so $\mathrm{v}$ tem obdobju zaostajale za $10-20 \%$ za slovenskim povpreðjem. Na voljo ni bilo investicijskih programov za vodilne industrijske panoge kot na primer za kovinsko, lesno, elektroindustrijo in elektroniko.

Struktura mariborske industrije je precej raznolika. Od 33 industrijskih panog v Sloveniji(1989) je bilo v Mariboru razvitih kar 24 panog. Takšna struktura naj bi omogočala vě̌jo prilagodljivost tržnim razmeram, vendar pa se mariborska industrija zaradi pomanjkanja znanja (sive 
substance) ni znala prilagoditi povpraševanju na trgu. Zato $\mathbf{v}$ zadnjih letih beleži upadanje izvoza. Tudi tecajna politika je povzroxila, da je bilo naše blago nekonkurenčno na tujem tržišcu. Seveda pa to ne velja za vsa podjetja. Nekatera so bila kljub vsemu uspešna. V Mariboru z okrog $40 \%$ prevladuje delovno intenzivna industrija (tekstilna, industrija usnja in obutve), kapitalno intenzivna(kemiæna, kovinska, živilska) in kapitalno-tehnoloß̌ko intenzivna pa dosegata do $30 \%$ vseh kapacitet. S $70 \%$ prevladuje proizvodnja șredstev za delo, $30 \%$ pa odpade na proizvodnjo potrošnega blaga. Leta 1988 je bilo največ zaposlenih $\mathbf{v}$ avtomobilski industriji, ki so ji sledile proizvodnja preje in tkanin, predelava kovin, proizvodnja elektrixnih strojev in aparatov ter proizvodnja končnih tekstilnih izdelkov. V primerjavi s preteklim obdobjem se struktura ni bistveno spremenila.

V Mariboru je še vedno mox̌no poudarjena industrijska funkcija. Mesto se je v zacetku 70-tih let znašlo pred hudimi urbanističnimi problemi, ki so terjali velike investicije. Vse to je mestno gospodarstvo precej izcrpalo, tako da je bilo konec leta 1989 stanje v industriji že kritično.

Industrija se je $\mathrm{v}$ tem obdobju se bolj razSirila $\mathrm{v}$ prostoru. Zaradi pomanjkanja povrక̌in, prostorske stiske in konfliktnih situacij $\mathrm{v}$ mestu so $\mathrm{v}$ tem obdobju odprli novo skladišcno-transportno-trgovsko cono na Teznu med železniško progo in cesto Maribor-Ljubljana. Vendar pa $\mathrm{v}$ tej coni, razen redkih izjem ne zasledimo industrijskih podjetij(Talis,Dinos). Na starih lokacijah se je industrija brezobzirno Sirila na sosednje parcele.

\subsection{OBDOBJE TRŽNEGA GOSPODARSTVA PO LETU 1989}

Leto 1989 je nov gospodarski mejnik, ki pomeni dejanski prehod na tržno gospodarstvo. V letu 1990 so bili $\mathrm{z}$ zakonom o podjetjih ukinjeni TOZD-i, tako da je prišlo tudi do bistvenih organizacijskih sprememb. Nekateri Tozd-i so se celo osamosvojili in postali samostojna podjetja (TIPPO, Družbeno podjetje Kruh -pecivo). V stevilnih OZD pa so se TOZD-i združili v enovita podjetja. Kriza $\mathbf{v}$ mariborski industriji je po tem letu $\mathrm{z}$ vso silovitostjo udarila na plan. Številna podjetja so bila in so క̌ pred steðaji (Lilet, Marles, Elektrokovina). Velike težave pa imajo skoraj vsa podjetja $\mathrm{v}$ mestu, predvsem pa giganti(Metalna, TAM, MTT). Posledica tega je bilo naglo odpušcanje delavcev, ki ga v obdobju samoupravnega socializma nismo poznali. Krizo v mariborski industriji pa so se dodatno zaostrile gospodarska blokada Srbije (1990), zalivska in slovenska vojna (1991). Od leta 1987 do leta 1991 se je Stevilo zaposlenih v mariborskih podjetjih zmanjšalo za približno 7700 delavcev, tako da je danes $v$ industriji zaposlenih §e 29000 ljudi. 


\section{LITERATURA IN VIRI}

Bajt,A., 1989. Gospodarska reforma. Enciklopedija Slovenije st. 3, str.306, Ljubljana.

Bracič,V., 1983. Razvoj upravne ureditve v Mariboru. Kronika, ČSKZ, 1.31, st.2-3, str.229-239, Maribor.

Curk,J, 1966. Maribor(Urbanistǐno-gradbeni zgodovinski oris). ČZN, nova vrsta,2 , XXXVII,str.63-95, Maribor.

Elaborat o dosedanjem razvoju, stanju in možnostih za nadaljni razvoj gospodarstva v okraju Mariborr do leta 1961. 1958, Maribor.

Kržičnik,E., 1956. Gospodarski razvoj Maribora. Maribor

Kržiennik,E.,Jurhar,S., 1981. Osnovne znacilnosti dosedanjega razvoja in doseženega stanja občine Maribor ter poskus opredelitve vzrokov zanj.EC Maribor in VEKŠ Maribor, Maribor. Leskovec,A., 1991. Razvoj gospodarstva v Mariboru 1752-1941. Tipkopis, Maribor.

Oreßnik,J., 1935. Teritorialni razvoj Maribora. Kronika slovenskih mest II.,Yt.2, str.122-126, Ljubljana.

Osnovne znaCilnosti družbenoekonomske politike obCine Maribor v letu 1972. 1972, Maribor. Porozilo o razvoju gospodarstva mesta Maribor za leto 1953. 1953, Maribor.

\section{THE DEVELOPMENT OF INDUSTRY IN MARIBOR WITH A SPECIAL STRESS ON DEVELOPMENT FACTORS}

The industry in Maribor began to develop in the second half of the 19th century when the South railway track Vienna-trieste was built. The railway track was of the greatest significance in the first stage of industrialization, lasting till the end of the First World War. After the First World War the textile and the metal industry grew to be important factors of the economical development in Maribor. The two industry branches could development owing to the advantegeous traffic position by the South railway track, sufficient quantity of electrical energy provided by hydroelectric power-plants on the river Drava, cheap manpower and the Yugoslav economical policy that attracted foreign investors for its general feeling of safety. The closeness of the sources of electrical energy was of vital importance for the industrial development in this period. During the Second World War, Maribor was the most ruined and damaged town in Slovenia, its inđustry paying its toll as well. The first years after the war were marked by reconstruction, nationalization of industrial plants and means of production(1946-1948), merging of large numbers of minor factories into big companies, and carrying out the first five-year-economical plan. The major part of means was earmarked for the development of heavy industry and electrification of the country. That is why the situation in the already obsolete textile industry got worse yet and the 50s brought a certain stagnation in the economy of Maribor. After the Second World War the leading part was taken by the product- 
ion of means of transport and textile industry, followed by metal, electrotehnical and timber industry.

In the last years Maribor was cought by a severe economical crisis which is a result of unsuitable structure and output orientation of the industry in the town, of tehnical and technological backwardness and slow introduction of various inovations into the industrial production. A big share of these problems is due to unsuitable industrial policy. Besides, the numerous companies going bankrupt, workers being dismissed from work, the ever growing of the unemployed, the standard of living growing worse and a general economic regression have brought a general feeling of depression, hopelessness and prospectless situation. 